\title{
Bonded composite repair structures multiple site damage analysis
}

\author{
Chi Chen, Thanh Hai Tran and Alex A. Volinsky \\ Department of Mechanical Engineering, University of South Florida, Tampa, Florida, USA
}

\begin{abstract}
Purpose - The purpose of this work is to describe the effects of the length of cracks and the patch size on the stress intensity factors in a bonded composite repair structure containing multiple site damage.

Design/methodology/approach - Finite element method was applied to simulate a bonded repair of a cracked aluminum plate with multiple site damage. A two-dimensional three-layer technique was utilized to model damage in a typical aluminum plate with collinear twin cracks.

Findings - This research has found that the stress intensity factors of collinear twin cracks can be reduced significantly through bonded composite repair, and their values strongly depend on the relative position of the cracks. Moreover, the composite patch should be 1.5 to two times longer than the crack length and the patch thickness should be 30-40 percent of the plate thickness for the best repair performance.

Research limitations/implications - Patch debonding can significantly reduce the repair efficiency and should be avoided if possible.

Originality/value - It is seen that, instead of the three-dimensional finite element model, which is computationally intense, the two-dimensional three-layer finite element model has an adequate accuracy to obtain stress intensity factors in a bonded composite repair structure with multiple site damage.
\end{abstract}

Keywords Bonded composite repair structure, Finite element analysis, Multiple site damage, Stress intensity factor, Stress (materials), Materials

Paper type Research paper

\section{Introduction}

Multiple sites damage (MSD) is typical for aged aircrafts and usually appears in the form of multiple cracks of varying length and direction. In aircraft structures, MSD cracks usually array along rivet holes in the fuselage and wings. These cracks can greatly reduce the structure strength and lifetime, affecting the flight safety. Multiple long cracks may have higher stress intensity than a single crack of the same length, thus they are more dangerous, as will be shown in this paper. Bonded patch repair is an effective way to mitigate MSD, thus aircraft structure durability and damage tolerance can be increased.

Research of bonded composite repair with and without utilizing finite elements (FEs) began in the early 1970s. Lots of work has been done on bonded composite repair structures with a single crack from the standpoint of design, analysis and experiments. Baker monitored a bonded composite patch repair on a fatigue-cracked F-111C wing (Baker, 2008). Xiong and Shenoi (2008) screened a bonded composite patch repair scheme for cracked aluminum alloy panels, based on static and fatigue strength concepts. Mall and Naboulsi (1996) used a 2D three-layer FE model to simulate a plate with a crack and an adhesive layer with a patch as the repair structure. Variation of the stress intensity factor (SIF) values of a crack in the plate before and after repair was analyzed.

The current issue and full text archive of this journal is available at www.emeraldinsight.com/1748-8842.htm

Aircraft Engineering and Aerospace Technology: An International Journal 85/3 (2013) $171-177$

(C) Emerald Group Publishing Limited [ISSN 1748-8842] [DOI 10.1108/00022661311313560]
Effects of patch debonding on the SIF values were discussed. Besides, nonlinear factors were considered in the bonded repair analysis (Mall and Naboulsi, 1996). The effects of geometry, size and adhesive layer parameters on the damage tolerance of the repair structure were studied. Regarding work done with 3D FE simulations, Seo and Lee (2002) investigated the fatigue crack propagation in the repair structure of a thick plate and obtained the crack tip SIF values with 3D FE analysis. Lee and Woo-Yong (2004) used successive $3 \mathrm{D} \mathrm{FE}$ analysis to simulate fatigue crack propagation in the repair structure. Ellyin et al. (2007) also utilized $3 \mathrm{D} \mathrm{FE}$ analysis to capture the effects of plasticityinduced crack closure on an adhesively bonded patch repair of a cracked plate. The 3D FE analysis is more accurate for bonded repair structure analysis, but it is computationally intense. There are not many reports dealing with bonded repair structures with MSD. One of them is the work of Tavares et al. (2008), which obtained the SIF of the two collinear cracks by 2D FE simulation, but without a repair structure.

Much work has been done on bonded repair structures with a single crack using both $2 \mathrm{D}$ and $3 \mathrm{D}$ FE simulations, however, research of the repair structure with MSD is rare. In this paper, FE simulation was used on bonded repair of aluminum plates with MSD. A 3D simulation is believed to be the best approach. However, in this paper, the 2D three-layer model was used to deal with the damage area, and showed that it is sufficient to obtain an accurate solution. A typical aluminum plate with collinear twin cracks MSD was considered. The effects of the crack lengths of the two cracks, the patch length, and the patch thickness on the corresponding SIFs were studied as well.

The authors acknowledge support from the National Science Foundation. 


\section{SIF of a MSD plate after repair}

In this paper, a $2 \mathrm{D}$ three-layer FE model was used to simulate the cracked plate, the adhesive layer and the composite patch. In the model, adhesive layer was simulated as an elastic continuum, instead of the spring elements. A general purpose $\mathrm{FE}$ analysis package was used in the investigation along with the direct method to obtain the SIFs. This model is simple and fast to implement, with the accuracy close to the 3D FE analysis. In Mall and Naboulsi's (1998) 2D three-layer model, Mindlin plate elements were used to simulate the three layers, and the modified crack closure method was used to obtain the SIFs (Mall and Naboulsi, 1998). Based on the assumption that the deformation variation is linear along the element thickness, the SIFs on the cracked plate free side had to be obtained by interpolation (Mall and Naboulsi, 1996). While in Mall and Naboulsi's (1996) the authors analyzed bonded repair structure with a single crack. In this paper, bonded repair structure with multiple cracks is analyzed.

In linear elastic fracture mechanics, the crack tip SIF values can be simply obtained with the FE direct method. In the direct method stress or deformation near crack tips is obtained with FE analysis first, and then the crack tip SIF values are calculated, based on the stress field. There are two direct methods commonly used, the displacement method with non-singularity elements and the stress method (Chan et al., 1970; Kobayashi et al., 1969).

\section{The displacement method}

From the displacements near the crack tip area and the SIF relationship in case of the plane stress problem, which applies to the model in this work, the mode I SIF, $K_{1}$, can be obtained from the node displacement, calculated by $\mathrm{FE}$ simulation:

$$
K_{1}=\frac{E u}{4\left(1-\nu^{2}\right)} \sqrt{\frac{2 \pi}{r}}
$$

Here, $E$ is the Young's modulus, $\nu$ is the Poisson's ratio, $r$ and $\theta$ are the polar coordinates with an origin at the crack tip, and $u$ are the crack surface displacements. Some nodes displacements are selected to produce the $K_{1}-r / a$ curve, where $a$ is the crack half-length. In a small area, where $r /$ $a \rightarrow 0, K_{1}$ can change abnormally, since the regular elements used are not able to reflect the crack tip singularity. In order to increase the calculation accuracy, the linear part of the $K_{1}-r / a$ curve can be extended to the vertical $K_{1}$ axis, making an intersection at $r / a=0$. The axis intersection point yields the $K_{1}$ value.

\section{The stress method}

Similar to the displacement method, the mode I SIF, $K_{1}$, can be obtained from the relationship between the crack stress field and the SIF:

$$
K_{1}=\sigma_{i j} \frac{\sqrt{2 \pi r}}{f_{i j}(\theta)}
$$

where:

$$
\begin{aligned}
& f_{x x}(\theta)=\cos (\theta / 2)[1-\sin (\theta / 2) \sin (3 \theta / 2)] \\
& f_{y y}(\theta)=\cos (\theta / 2)[1+\sin (\theta / 2) \sin (3 \theta / 2)] \\
& f_{x y}(\theta)=f_{y x}=\sin (\theta / 2) \cos (\theta / 2) \cos (3 \theta / 2)
\end{aligned}
$$

Similarly, extending linear part of the $K_{1}-r / a$ curve to $r /$ $a=0$, yields the SIF value. In this work $\sigma_{y y}$ was used at $\theta=0^{\circ}$ to obtain the SIF value.

\section{Finite element model}

A 2D three-layer FE model was utilized to simulate the cracked aluminum plate with the adhesive layer and the composite patch layer. Variations of crack tip SIF in the plate before and after patch repair were obtained by $\mathrm{FE}$ simulation.

\section{Basic assumptions}

Basic assumptions were made, based on the actual conditions of the bonded repair structure, in order to simplify calculations:

- The cracked plate and the patch thickness are much smaller than their in-plane dimensions, i.e. plane stress condition. The structure deformations are linear elastic.

- The adhesive is an isotropic material, in which only shear deformations are considered. For the one-side repair, the out of plane bending caused by structural asymmetry is not considered.

- All adhesive areas are perfectly bonded.

\section{Finite element model validation}

The same material properties and geometry, as those presented in Mall and Naboulsi (1996), were used to verify the FE model accuracy and to analyze the repair performance of boron/epoxy composite. Presented model accuracy is verified by comparisons shown in Table I. The obtained normalized SIF is larger than the Sun's 2D result (Sun et al., 1996), and is in-between the Papanikos et al.'s (2005) and the Chau's (2000) 3D models; it is close to the Mall and Naboulsi's (1996) result. Based on this comparison, the presented model can reflect the actual structure conditions and reasonably satisfy the calculation accuracy requirements.

Model geometry and materials mechanical properties A 2D three-layer model is based on the aluminum plate geometry with collinear twin cracks. The specimen is made of $2024 \mathrm{~T} 3$ aluminum alloy with the length of $200 \mathrm{~mm}$, the width of $80 \mathrm{~mm}$, and the thickness of $2 \mathrm{~mm}$. Adhesive is FM73 epoxy with a thickness of $0.2 \mathrm{~mm}$. Composite patch is made of boron/epoxy laminate. The materials mechanical properties are presented in Table II, obtained from Schubbe and Mall (1999). The patch width in this model is the same as the plate width for comparison purposes, and the patch length is $40 \mathrm{~mm}$. The model geometry is shown in Figure 1. The patch is bonded on one side of the plate and fully covers the cracks.

Table I Validation of the FE model

\begin{tabular}{lccccc}
\hline & \multicolumn{1}{c}{ Mall and } & & & \\
Models & Naboulsi & Chau & Sun et al. & Sun et al. \\
paper 2D & $(1996)$ 2D & $(2000)$ 3D & (1996) 2D & (1996) 3D \\
\hline $\begin{array}{l}\text { Normalized } \\
\text { SIF value } \\
K=\frac{K_{1}}{\sigma_{y} \sqrt{\pi a}}\end{array}$ & 0.564 & 0.570 & 0.481 & 0.536 & 0.612 \\
\hline
\end{tabular}


Chi Chen, Thanh Hai Tran and Alex A. Volinsky

Table II Materials mechanical properties

\begin{tabular}{lccccc}
\hline Mechanical properties & $\begin{array}{c}E_{1} \\
(\mathrm{GPa})\end{array}$ & $\begin{array}{c}E_{23} \\
(\mathrm{GPa})\end{array}$ & $\boldsymbol{v}$ & $\begin{array}{c}G_{12}, G_{13} \\
(\mathrm{GPa})\end{array}$ & $\boldsymbol{G}_{23}(\mathrm{GPa})$ \\
\hline Aluminum plate & 70 & - & 0.32 & - & - \\
Adhesive layer & 1 & - & 0.32 & - & - \\
Boron/epoxy & 208 & 25.4 & 0.17 & 7.2 & 4.9
\end{tabular}

Notes: Here, $E$ - Young's modulus, $G$ - Shear modulus, $\nu$ - Poisson's ratio; 1,2 , and 3 are the in-plane, transverse and out-of-plane transverse fiber directions, respectively

Source: Schubbe and Mall (1999)

\section{Boundary conditions}

In this FE analysis, four-node shell elements were used to simulate the cracked plate, the adhesive layer and the composite patch. The mesh density was higher near the crack tips. Only half of the structure was modeled due to its symmetry. One side of the model was added with symmetric boundary conditions, and the other side was added with the distributed load. Direct method was used to obtain the SIF values. FE mesh of the entire model and the cracks is shown in Figure 2.

\section{Results and discussion}

Based on multiple FE simulations, the following results were obtained.

\section{SIF variation with the crack length}

Figure 3 compares the normalized SIFs of a single crack obtained from a closed-form solution (Murakami, 2003) and twin collinear cracks of different length. SIFs were normalized by $\sigma \sqrt{\pi a}$, making normalized $K=K_{1} / \sigma \sqrt{\pi a}$ unitless, while the crack length was normalized by the plate width. In Figure 3, the normalized SIFs of the left crack (tip A) and the right crack (tip B), as shown schematically in Figure 4, are plotted as functions of normalized crack length. Compared with a single crack, collinear twin cracks have smaller SIFs for shorter normalized crack length $(2 a / w<0.2)$, and thus a single crack is more likely to propagate in this case. The SIFs for the twin cracks depend on the relative distance between those cracks, and between the cracks and the plate boundary. When the distance between the tips of collinear twin cracks is between 55 and 60 percent of the distance between their centers $(d / D=55$ percent, see Figure 4), the SIF values of the twin crack tips are close to those of the single crack. After that, at larger crack lengths, $K_{1}(\mathrm{~B})$ and $K_{1}(\mathrm{~A})$ increase and exceed SIF values of a single crack, respectively. Twin cracks are more likely to propagate in this case, compared with the single crack of the same length.

\section{Patched and unpatched plates SIFs variation with the crack length}

Comparison of the SIF values between the patched and unpatched twin cracks of varying length is shown in Figure 5. Variation of SIF values shows that bonded repair with composite patch can greatly reduce the SIFs of collinear twin cracks. Larger SIFs reduction (the difference between the repaired and un-repaired SIFs) is seen for longer cracks. The difference between the SIF values of the A and B cracks in the unpatched plate increases with the crack length. Patch repair decreases the SIFs by over 90 percent, and after repair, there is almost no difference between the A and B cracks SIFs, signifying the repair efficiency.

\section{Patch length effect on the SIF values}

Let's consider a certain fixed crack half-length $a=10 \mathrm{~mm}$, and then calculate SIFs for A and B cracks after repair with varying patch length. The results of this exercise are shown in Figure 6. With increasing patch length, SIFs decrease, thus the repair performance improves. When the patch is small, increasing its length has a positive effect on the load transfer from the cracked plated to the composite patch through an adhesive layer, thus releasing the load concentration near the crack tips. However, when the patch length reaches a certain value, the SIF of the repair model increases and the repair

Figure 1 Schematics of the model geometry

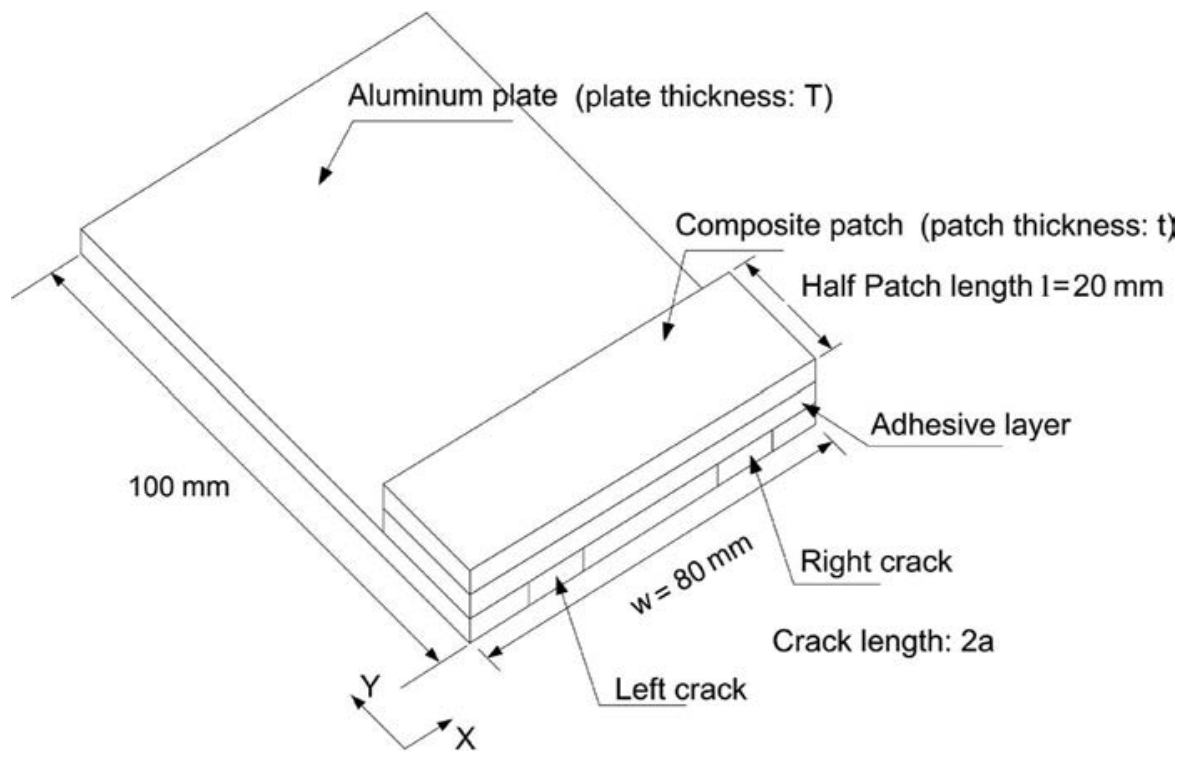


Figure 2 (a) FE mesh of the entire model and (b) the crack

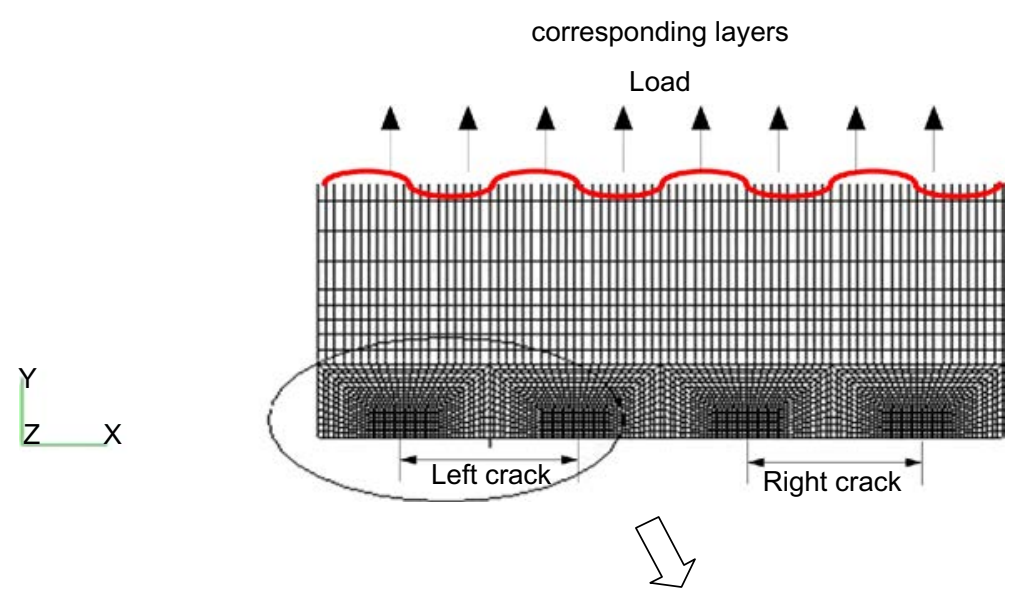

(a)

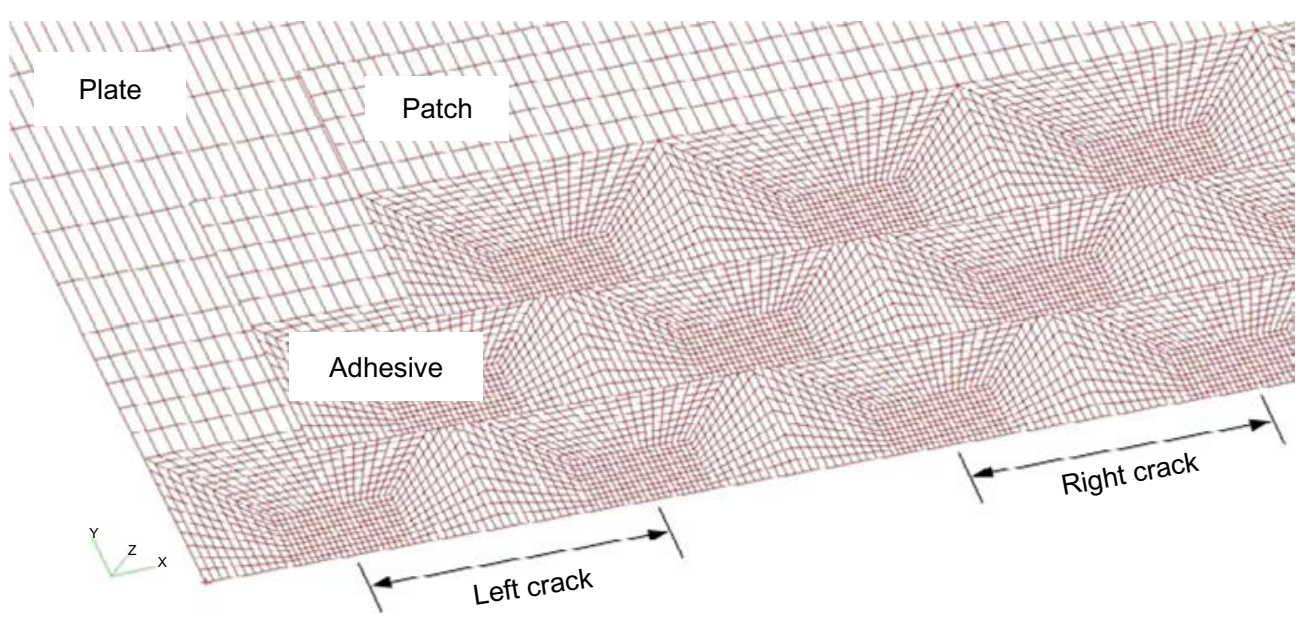

(b)

Note: Here, plate, patch and adhesive represent corresponding layers

Figure 3 Comparison of the normalized SIFs values between a single crack and twin cracks of varying length

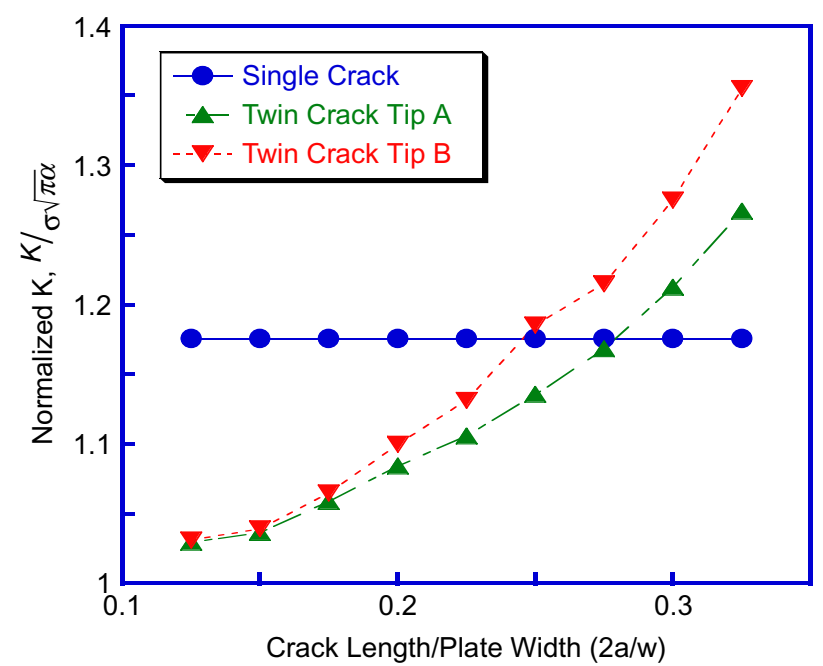

Note: The single crack SIFs were obtained from Fernand et al. (2007)
Figure 4 Twin cracks geometry configuration

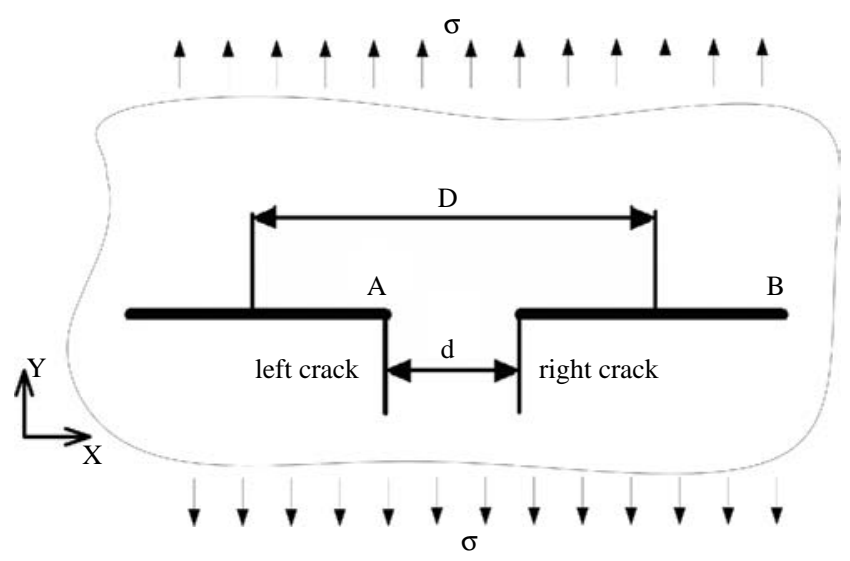

performance declines. This phenomenon is due to two effects. First, there is only a small area of the adhesive layer near the joint that can effectively transfer the load by shear. In the longer part of the joint, the adhesive layer transfers less load (Endogan and Ratwani, 1971). This situation makes a patch 
Figure 5 Comparison of the SIFs values between patched and unpatched twin cracks of varying length

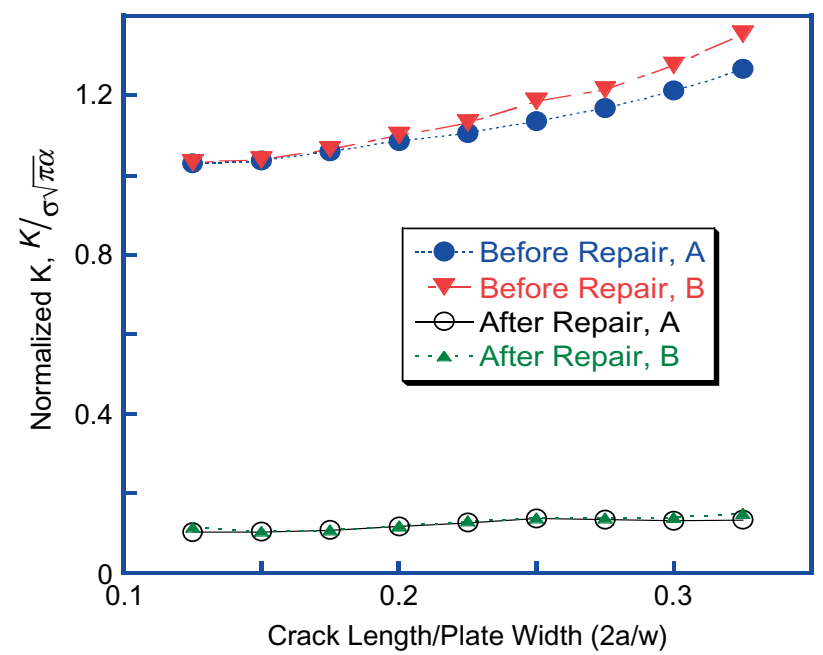

Figure 6 Effect of the patch length on the normalized SIF values of the repaired structure

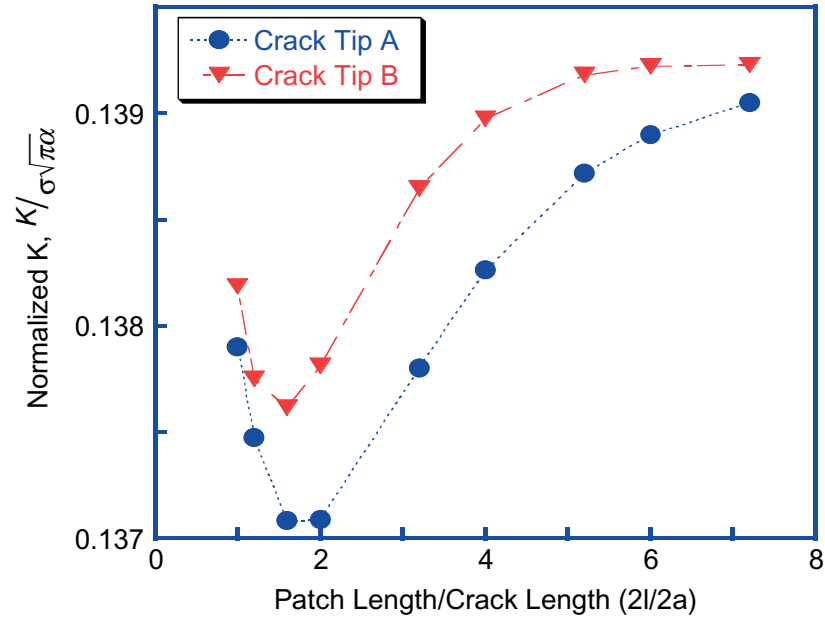

layer behave like a staple, which pulls the crack sides together. If the staple is too long, or too short, it is less effective in reducing the crack opening. Additionally, the local stiffness of the patched area in the cracked plate increases after repair, improving the load transferred in the patched area. When the patch length is over seven to eight times of the crack length, the SIFs tend to plateau. Therefore, an optimal patch length is around 1.5 to two times longer than the crack length, for which the SIFs are at their minimum values, which guarantees the best repair performance.

\section{Layout effect on the SIF values}

Let's consider the crack half-length, $a$, of $10 \mathrm{~mm}$, the patch thickness of $0.8 \mathrm{~mm}$, and calculate the SIF value of the repaired cracked plate with $0^{\circ}, 90^{\circ}$ and $[0 / \pm 45 / 90]_{2 \mathrm{~s}}$ fibers layout, respectively. This comparison is presented in Table III. The repair performance is relatively poor with the composite patch, which $0^{\circ}$ layout is along the $\mathrm{x}$ (crack) direction, perpendicular to the applied load. The repair performance
Table III Fiber layout effect on the SIFs

\begin{tabular}{lccc}
\hline Patch layout & $\begin{array}{c}0^{\circ} \text { layer } \\
\text { X direction }\end{array}$ & $\begin{array}{c}0^{\circ} \text { layer } \\
\text { direction }\end{array}$ & {$[0 / \pm 45 / 90]_{2 s}$} \\
\hline Normalized SIF after repair & 0.401 & 0.059 & 0.137 \\
\hline
\end{tabular}

is the best for the composite patch, which $0^{\circ}$ layout is along the y loading direction. The repair performance of the $[0 / \pm 45 / 90]_{2 \mathrm{~s}}$ layout is in-between the two cases presented.

\section{Patch thickness effect on the SIF values}

Figure 7 shows the patch thickness effect on the A and B crack tips SIFs. With increasing patch thickness, the SIF of the patch repaired structure decreases, and the repair performance improves. However, with further patch thickness increase, the repair performance plateaus. Besides, if the patch thickness is too large on one side of the patch repair, the out-of-plane bending moment cannot be neglected, causing a side negative effect on the repair performance (Yang and Volinsky, 2004). The patch thickness needs to be optimized, based on the actual loading conditions. In general, the patch thickness on the order of 30-40 percent of the plate thickness will provide adequate decrease in $\mathrm{K}$, as shown in Figure 7.

\section{Patch debonding}

Debonding can occur around cracks due to fatigue (Schubbe and Mall, 1999). Patch debonding can be more severe when applied load increases (Papanikos et al., 2005). The size of debonded area has an important effect on the repair performance (Colombi et al., 2003). Larger debonded area lowers the repair efficiency. In this paper, debonding can be simulated by releasing the node constraints between the adhesive layer and the aluminum plate. The approximate reduction of repair efficiency can be as high as 80 percent in case of full width debonding, when the debonded area reaches 50 percent of the overall patch area.

In addition, one has to consider thermal and environmental effects that can lead to patch debonding. Temperature cycling can also cause fatigue interfacial cracks. Patch debonding can also be induced by environmental effects, where moisture substantially reduces adhesion (Waters and Volinsky, 2006).

Figure 7 Patch thickness effect on the SIFs values of the repaired structure

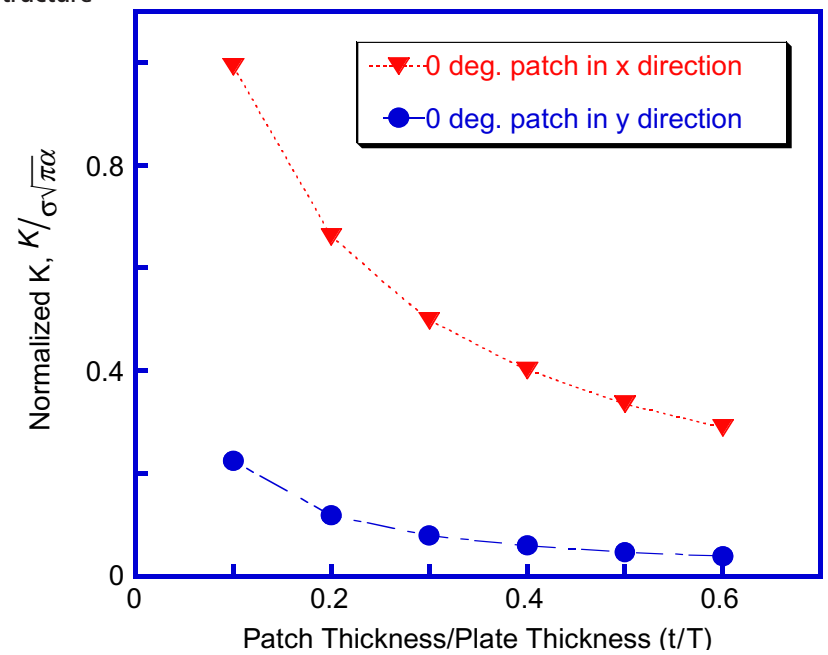


Trapped at the interface, moisture turns into ice in flight, loading and propagating interfacial defects that grow into interfacial cracks. Nevertheless, successful patch repairs have been demonstrated for commercial aircrafts (Rarthlomeusz et al., 1993; Roach and Rackow, 2007).

\section{Conclusions}

2D three-layer FE model can be used to calculate the SIFs of collinear twin cracks with an adequate accuracy. The relative position of collinear twin cracks has significant effect on the crack tip SIFs in certain stress fields. When the distance between the tips of collinear twin cracks is larger than 55 percent of that between their centers, the SIF can be calculated as for the single crack. For this condition, the SIF obtained is conservative. When the distance between the collinear twin cracks tips is less than 55 percent of that between their centers (larger crack length), the SIF of twin cracks will exceed that of the single crack, requiring repair. Multiple site damage is worse than a single crack, and definitely needs to be repaired. The SIFs of collinear twin crack can be reduced by over 90 percent through bonded composite repair. The longer the crack length, the better the repair performance is. However, for certain cracks and stress fields, parameters, such as the adhesive properties, patch length and thickness must be optimized in order to obtain the best patch repair performance. Patch length needs to be 1.5-2 times the crack length to minimize the SIF of the multiple site damage. Larger than needed patch size and thickness are not beneficial. Patch debonding should be avoided, or controlled to a limited area.

\section{References}

Baker, A. (2008), "Structural health monitoring of a bonded composite patch repair on a fatigue-cracked F-111C wing", Defence Science and Technology Organisation, Accession number ADA485406, Media count 52.

Chan, S.K., Tuba, I.S. and Wilson, W.K. (1970), "On the finite element method in linear fracture mechanics", Engineering Fracture Mechanics, Vol. 2 No. 1, pp. 1-17.

Chau, W.T. (2000), "Bonded repair of a center-cracked panel with composite patches", $\mathrm{PhD}$ thesis, University of Science and Technology, Hong Kong.

Colombi, P., Bassetti, A. and Nussbaumer, A. (2003), "Delamination effects on cracked steel members reinforced by prestressed composite patch", Theoretical and Applied Fracture Mechanics, Vol. 39 No. 1, pp. 61-71.

Endogan, F. and Ratwani, M.M. (1971), "Stress distribution in bonded joints", fournal of Composite Materials, No. 5, pp. 378-393.

Fernand, E., Folarin, O. and Zihui, X. (2007), "3-D modelling of cyclically loaded composite patch repair of a cracked plate", Composite Structures, Vol. 78 No. 4, pp. 486-494.

Kobayashi, A.S., Maiden, D., Simon, B. and Iida, S. (1969), "Application of finite element analysis method to twodimensional problems in fracture mechanics", paper presented at ASME Winter Annual Meeting.

Lee, J.J. and Woo-Yong, L. (2004), "Successive 3D FE analysis technique for characterization of fatigue crack growth behavior in composite-repaired aluminum plate", Composite Structures, Vol. 66 Nos 1-4, pp. 513-520.
Mall, S. and Naboulsi, S. (1996), "Modeling of a cracked metallic structure with bonded composite patch using the three layer technique", Composite Structures, Vol. 35 No. 3, pp. 295-308.

Mall, S. and Naboulsi, S. (1998), "Nonlinear analysis of bonded composite patch repair of cracked aluminum panels", Composite Structures, Vol. 41 Nos 3/4, pp. 303-313.

Murakami, Y. (2003), Stress Intensity Factors Handbook, Elsevier, New York, NY, p. 200.

Papanikos, P., Tserpes, K.I., Labeas, G. and Pantelakis, S. (2005), "Progressive damage modelling of bonded composite repairs", Theoretical and Applied Fracture Mechanics, Vol. 43 No. 2, pp. 189-198.

Rarthlomeusz, R.A., Paul, J.J. and Roberts, J.D. (1993), "Application of bonded composite repair technology to civil aircraft - B747 demonstration programme", Aircraft Engineering E Aerospace Technology, Vol. 65 No. 4, pp. 4-7.

Roach, D. and Rackow, K. (2007), "Development and validation of bonded composite doubler repairs for commercial aircraft", Sandia Report, SAND2007-4088, p. 220.

Schubbe, J.J. and Mall, S. (1999), "Modeling of cracked thick metallic structure with bonded composite patch repair using three-layer technique", Composite Structures, Vol. 45 No. 3, pp. 185-193.

Seo, D.C. and Lee, J.J. (2002), "Fatigue crack growth behavior of cracked aluminum plate repaired with composite patch", Composite Structures, Vol. 57 Nos 1-4, pp. 323-330.

Sun, C.T., Klug, J. and Arendt, C. (1996), "Analysis of cracked aluminum plates repaired with bonded composite patches", AIAA fournal, Vol. 34 No. 2, pp. 369-374.

Tavares, S.M.O., Moreira, P.M.G.P., Pastrama, S.D. and Castro, P.M.S.T. (2008), "Stress intensity factors by numerical evaluation in cracked structures", paper presented at 11th Portuguese Conference on Fracture, Lisbon, February 13-15.

Waters, P. and Volinsky, A.A. (2006), "Stress and moisture effects on thin film buckling delamination", Experimental Mechanics, Vol. 47 No. 1, pp. 163-170.

Xiong, J.J. and Shenoi, R.A. (2008), "Integrated experimental screening of bonded composites patch repair schemes to notched aluminum-alloy panels based on static and fatigue strength concepts", Composite Structures, Vol. 83, pp. 266-272.

Yang, Q.D. and Volinsky, A.A. (2004), "Effects of near-tip rotation on pre-buckle crack growth of compressed beams bonded to a rigid substrate", International fournal of Solids and Structures, Vol. 41, pp. 2711-2729.

\section{About the authors}

Chi Chen completed his M.S. degree in 2009 at the University of South Florida, Department of Mechanical Engineering, thesis title "2-D finite element modeling for nanoindentation and fracture stress analysis". He is currently pursuing his $\mathrm{PhD}$ degree at the University of Miami.

Thanh Hai Tran is currently pursuing his PhD degree at the University of South Florida, Department of Mechanical Engineering. 
Alex A. Volinsky is an Associate Professor at the University of South Florida, Department of Mechanical Engineering. He obtained his PhD degree from the University of Minnesota, Department of Chemical Engineering and Materials Science in 2000. Thesis title: "The role of geometry and plasticity in thin, ductile film adhesion". Dr Volinsky held an Engineering Materials Senior Staff Member potion at Motorola's Process and Materials Characterization Lab prior to joining USF. There, he conducted principal research employing XRD, SEM, FIB, FA analytical techniques for advanced technologies development, including porous low-K dielectrics and interconnect structures. Professor Volinsky's current research interests are: thin films processing, mechanical properties and characterization; adhesion and fracture of thin films; microelectronics and MEMS reliability, environmental degradation of materials. $\mathrm{He}$ is in charge of the Nanomechanical Testing and X-Ray lab at USF. Dr Volinsky authored over 100 scientific papers, one of which was determined to be the most cited paper in the field of materials science in February 2004 by ISI Essential Science Indicators: A.A. Volinsky, N.R. Moody, W.W. Gerberich, Acta Mater, Vol. 50 No. 3, pp. 441-66, 2002. He organized several conferences and symposia. Professor Volinsky's research was recognized by national and international awards. Alex A. Volinsky is the corresponding author and can be contacted at: volinsky@usf.edu

To purchase reprints of this article please e-mail: reprints@emeraldinsight.com

Or visit our web site for further details: www.emeraldinsight.com/reprints 